\title{
A novel method of blind bedside placement of postpyloric tubes
}

\author{
Jia-Kui Sun, Xiang Wang ${ }^{*}$ and Shou-Tao Yuan ${ }^{*}$ \\ See related research by Lv et al., https://ccforum.biomedcentral.com/articles/10.1186/s13054-017-1839-2
}

We read with great interest the recent report on blind bedside postpyloric placement by Lv et al. [1]. Their methods were proven to be safe and effective in intensive care units. Although our placing procedure is similar to that reported by the authors, the choice of a postpyloric tube and the patient's position requires further improvement.

In our center, we use a $130-\mathrm{cm}$ long transpyloric tube with a guide wire $(\mathrm{CH} 10-130$, inner diameter 2.0-2.1 mm, Flocare, Nutricia Ltd, Wuxi, China; Fig. 1a) rather than the spiral feeding tube used by Lv et al. The Flocare tube that we used has several advantages compared with the spiral tube. First, the Flocare tube is inexpensive, approximately $\$ 22$, in China, whereas the spiral tube costs approximately $\$ 71$. Expense is extremely important in developing countries and at one-third less compared with the latter, our technique is easier to implement in hospitals and areas with limited resources. Second, the Flocare tube that we used has two side holes near its tip (Fig. 1b); therefore, it is less likely to be blocked compared with the spiral tube. Third, the guide wire is shorter in length compared with the Flocare tube; thus, the rigid tip would not damage the digestive tract during the placing procedure.
The patient's position before placing the postpyloric tube also requires further improvement. In our procedure, the patient is placed in a right decubitus position at $30-45^{\circ}$ after gastric placement is accomplished, followed by a postpyloric placement. According to our experience, in this position the tip of the Flocare tube falls to the pylorus ostium by gravity, which may increase the placement success rate.

The results of our data (unpublished) analysis confirmed our improved methods (Fig. 2). From December 2016 to December 2017, 44 patients underwent postpyloric tube placement using our novel techniques. In total, 38 cases $(86.4 \%)$ were successful, and 33 cases (75.0\%) were successful at the first attempt. The success rate and first-time success rate of our placement techniques were better than those described in the study by $\mathrm{Lv}$ et al. The median time of our procedure was 13 (8.5-16) minutes, and the median insertion length was $100(93.5-110) \mathrm{cm}$. These values are similar to the results of Lv et al. and other previous reports [1-3].

Considering the less expensive tube and better firsttime success rate, our novel blind bedside postpyloric placement may be easier to implement worldwide, and we look forward to collaborating with the authors and other colleagues. 


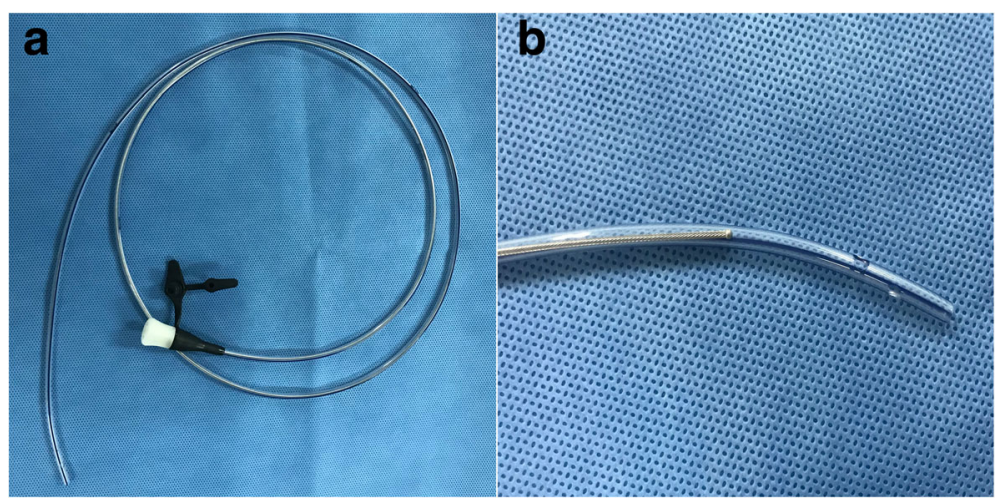

Fig. 1 The 130-cm long transpyloric tube with a guidewire ( $\mathrm{CH1}$-130, inner diameter 2.0-2.1 mm, Flocare, Nutricia Ltd, Wuxi, China) used in our center (a). This Flocare tube has two side holes near its tip (b)
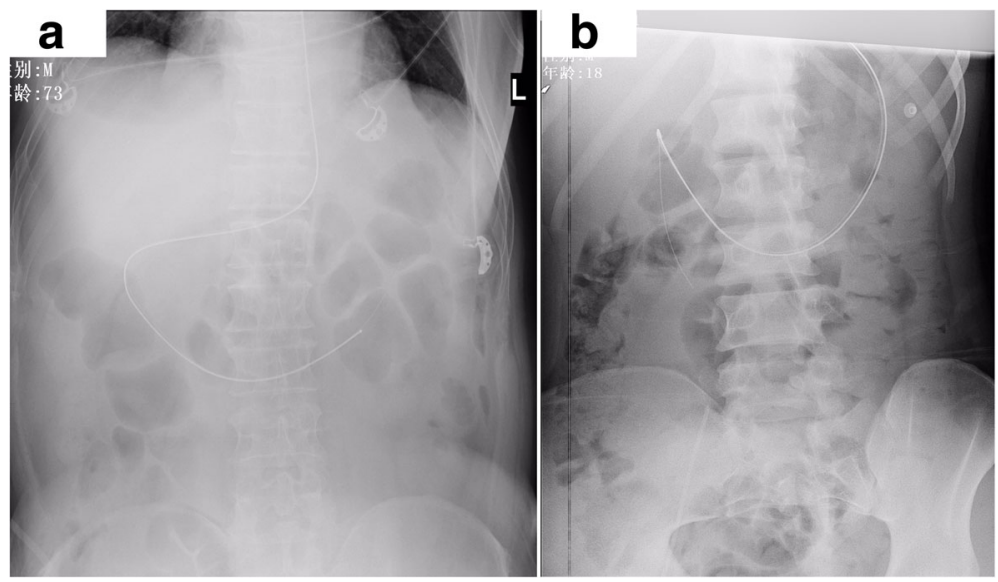

Fig. 2 Abdominal plain radiographs showing the tip of the Flocare tube positioned at the horizontal part (a) and descending part (b) of the duodenum. The former demonstrates the classic C-shaped duodenal configuration diagnostic of postpyloric placement

\section{Acknowledgements}

Not applicable.

\section{Funding}

This work was supported in part by grants from the National Natural Science Foundation of China (number 81701881), and the Nanjing Medical Science and Technology Development Foundation (number YKK15098, number YKK17102).

\section{Availability of data and materials}

Not applicable.

\section{Authors' contributions}

JKS, XW, and STY wrote the manuscript. All authors read and approved the final manuscript. The work has not been published previously nor is under consideration for publication elsewhere.

\section{Ethics approval and consent to participate}

Not applicable.

\section{Consent for publication}

Not applicable.

\section{Competing interests}

The authors declare that they have no competing interests.

\section{Publisher's Note}

Springer Nature remains neutral with regard to jurisdictional claims in published maps and institutional affiliations.

Received: 21 January 2018 Accepted: 9 February 2018 Published online: 09 March 2018

\section{References}

1. Lv B, Hu L, Chen L, Hu B, Zhang Y, Ye H, Sun C, Zhang X, Lan H, Chen C. Blind bedside postpyloric placement of spiral tube as rescue therapy in critically ill patients: a prospective, tricentric, observational study. Crit Care. 2017:21(1):248

2. Rollins CM. Blind bedside placement of postpyloric feeding tubes by registered dietitians: success rates, outcomes, and cost effectiveness. Nutr Clin Pract. 2013;28(4):506-9.

3. Kohata $H$, Okuda N, Nakataki E, Itagaki T, Onodera M, Imanaka H, Nishimura M. A novel method of post-pyloric feeding tube placement at bedside. J Crit Care. 2013;28(6):1039-41 